\title{
Incidental finding of thoracic outlet syndrome in a case of right tubal ruptured ectopic pregnancy
}

\author{
Niranjan Chavan*, Shalini Mahapatra, Meenakshi Ruhil, Shweta Mohokar
}

\begin{abstract}
Department of Obstetrics and Gynecology, Lokmanya Tilak Municipal Medical College and General Hospital,
\end{abstract} Mumbai, Maharashtra, India

Received: 26 December 2019

Revised: 24 July 2020

Accepted: 31 July 2020

\section{*Correspondence:}

Dr. Niranjan Chavan,

E-mail: mahapatra.shalini@gmail.com

Copyright: () the author(s), publisher and licensee Medip Academy. This is an open-access article distributed under the terms of the Creative Commons Attribution Non-Commercial License, which permits unrestricted non-commercial use, distribution, and reproduction in any medium, provided the original work is properly cited.

\begin{abstract}
A 30-year-old woman, (multigravida) suffering from lower abdominal pain and slight vaginal bleeding was transferred to our hospital. She came with a pelvic ultrasound report. The provisional diagnosis of right tubal ectopic pregnancy was made. A laparotomy was carried out. Intraoperatively, blood pressure in both the arms were taken which revealed different blood pressure in different arms. A diagnosis of thoracic outlet syndrome was made. No postoperative complications were observed.
\end{abstract}

Keywords: Ectopic pregnancy, Maternal morbidity, Ruptured ectopic pregnancy, Tubal pregnancy, Thoracic outlet syndrome

\section{INTRODUCTION}

Ectopic pregnancy occurs when a fertilized egg implants outside the uterine cavity. One out of every 100 pregnancy is ruptured ectopic with the most common site being within the fallopian tube1. Ectopic pregnancy is a potentially fatal emergency condition, if early diagnosis is missed. Ectopic pregnancy continues to be a leading cause of maternal morbidity during the first trimester. ${ }^{1}$ The presentation varies widely from being asymptomatic to haemodynamically compromised.

Thoracic outlet syndrome is a group of disorders that occur when blood vessels or nerves in the space between collarbone and first rib (thoracic outlet) are compressed. This can cause pain in shoulders and neck and numbness in fingers. ${ }^{2-4}$

\section{CASE REPORT}

Mrs. ABC 30 years old multigravida presented to emergency department with chief complains of sudden onset of abdominal pain for 4 hours. Her LMP was 6 weeks back. She was married for 5 years with previous 3 living children, normally delivered. She was hemodynamically unstable. Patient had tachycardia 110 beats/minute and hypotension with blood pressure of $80 / 50 \mathrm{mmHg}$. Abdominal examination revealed lower abdomen tenderness, guard in and rigidity. Per vaginal examination revealed tenderness in right fornix. Her $\beta$ hCG levels was $6000 \mathrm{mlU} / \mathrm{ml}$, significantly high and Hb$10 \mathrm{gms} \%$. Urine pregnancy test was positive. Pelvic ultrasound revealed empty uterine cavity with an anechoic area measuring $5 \times 4.6 \times 2.8 \mathrm{~cm}$ in right adnexa with embryo like echo (Figure 1). Mild free fluid was present in the pouch of Douglas.

Possibility of ectopic pregnancy was explained to her and relatives. Informed consent for exploratory laparotomy with right sided salpingectomy and left tubal ligation was taken and she was shifted to the operation theatre. An emergency exploratory laparotomy was performed with a preoperative provisional diagnosis of ruptured right tubal ectopic pregnancy. Intraoperative findings showed uterus 
and left tube was normal. Bilateral ovaries were normal. Right sided ruptured tubal ectopic of $6 \times 4 \times 2 \mathrm{~cm}$ was found along with $100 \mathrm{ml}$ of hemoperitoneum and blood clots of 20 gms (Figure 2). Hemoperitoneum was not as significant as the hypotension in the patient. Therefore, blood pressure in the other arm was taken which revealed different blood pressure in different arms. Blood pressure in the other arm was $100 / 80 \mathrm{mmHg}$.

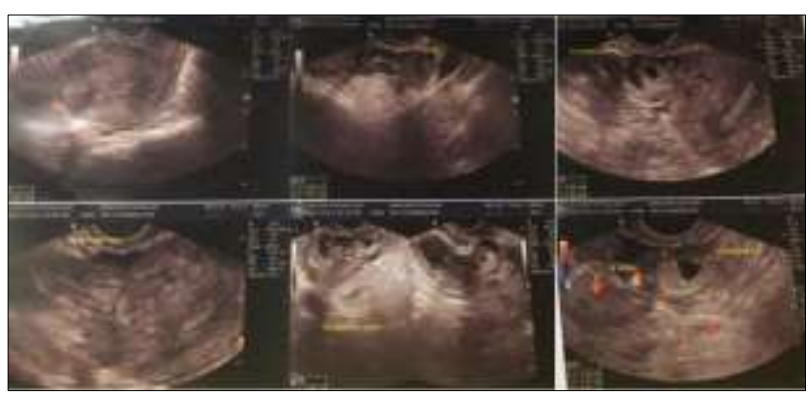

Figure 1: USG obstetric is suggestive of right ruptured ectopic pregnancy.

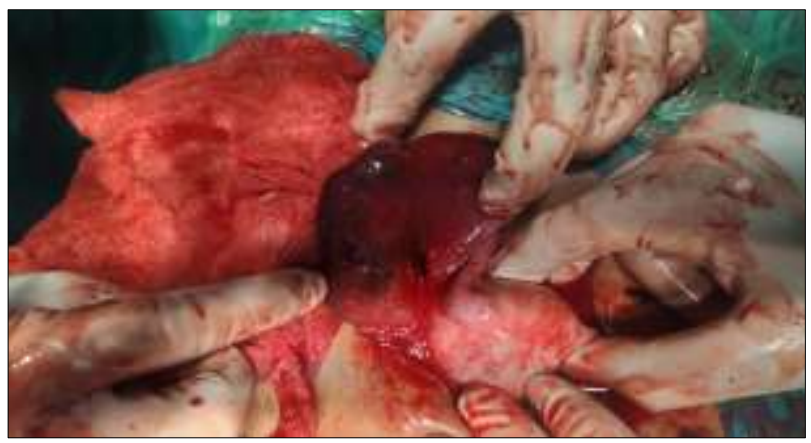

Figure 2: Right tubal ruptured ectopic pregnancy.

Right salpingectomy with left tubal ligation was done. Hemostasis was achieved and confirmed. Patient was transfused one pint of packed red cells intraoperatively. Post operatively medicine department, cardio vascular thoracic surgery (CVTS) department references were taken and upper limb Doppler was advised and done which showed marked wall thickening with luminal compromise in left subclavian artery. Contrast tomography angiogram was done suggestive of left thoracic outlet syndrome. Cervical rib was noted on left side with its distal most tip is abutting the anterolateral aspect of $1^{\text {st }}$ rib. No obvious bony fusion was noted between cervical and $1^{\text {st }}$ rib. Non opacified portion of left subclavian artery was abutting left cervical rib, features suggestive of left thoracic outlet syndrome. Repeat CVTS reference was taken. As patient was not having active symptoms no active intervention was advised and patient was asked to follow-up in out-patient department.

\section{DISCUSSION}

An ectopic pregnancy is any pregnancy implanted outside the endometrial cavity. In UK, Incidence is $11 / 1000$, with estimated 11,000 ectopic pregnancies diagnosed per year. ${ }^{1}$ Case fatality rates have decreased over recent years, suggesting earlier diagnosis and treatment.

Risk factors include tubal damage after surgery or infection, smoking and in vitro fertilisation. ${ }^{1}$

Incidence of thoracic outlet syndrome: less than 1 million case is seen per year. ${ }^{2}$ Symptoms like pain in the shoulders, neck and numbness and coldness in the fingers is seen. In thoracic outlet syndrome (TOS) there may be compression of the nerves, arteries, or veins in the passageway from the lower neck to the armpit. $^{2}$ Presenting types: neurogenic, venous and arterial. The neurogenic type is the most common, causing pain, weakness, and occasional loss of muscle at the base of the thumb. ${ }^{2}$ The venous type results in swelling, pain, and possibly a bluish coloration of the arm. The arterial type may cause pain, coldness, and paleness of the arm. Patient in this case report had no such symptoms making it even a rarer one. TOS may result from trauma, repetitive arm movements, tumours, pregnancy, or anatomical variations such as a cervical rib. The diagnosis may be supported by nerve conduction studies and medical imaging. ${ }^{3}$ In this case computed tomography angiography was done for Chauhan et al. ${ }^{4}$ MRI is preferred because of its ability to show bone, soft tissue, vascular and nerve abnormalities with its superior contrast and resolution. Limb MRI allows excellent imaging of vessels and can be an excellent diagnostic tool. Furthermore, MRI neurography can detect brachial plexus compression, contributing to the diagnosis of the neurogenic form of TOS. It is a rare condition affecting only $1 \%$ of the population. ${ }^{5}$ It is more common in women than men and it occurs most commonly between 20 and 50 years of age. ${ }^{5}$ The condition was first described in 1818 and the current term "thoracic outlet syndrome" first used in 1956. TOS can be attributed to one or more of the following factors: congenital abnormalities, like cervical rib, prolonged transverse process, and muscular abnormalities or fibrous connective tissue anomalies. ${ }^{6}$ Trauma (e.g., whiplash injuries) or repetitive strain is frequently implicated. Rarer acquired causes include tumours, hyperostosis, and osteomyelitis. ${ }^{7,8}$ Important differential diagnoses for the neurogenic form of TDS include: musculoskeletal disease (such as arthritis or tendonitis) of the cervical spine, shoulder girdle or upper arm, cervical radiculopathy or upper extremity nerve compression, idiopathic brachial plexus inflammation (also known as Parsonage syndrome). Turner and compression of the brachial plexus due to an infiltrative process or mass such as pulmonary apex pancoast tumor. ${ }^{9}$ Patient in this case had cervical rib on left side with its distal most tip is abutting the anterolateral aspect of $1^{\text {st }}$ rib.

\section{Funding: No funding sources Conflict of interest: None declared Ethical approval: Not required}




\section{REFERENCES}

1. RCOG green top guideline no. 21, 2016, Available at: $\quad$ https://www.rcog.org.uk/guidelines? $p=2$. Accessed on $12^{\text {th }}$ November 2019.

2. NINDS Thoracic outlet syndrome information page. NINDS. 2011. Available at: https://www.ninds.nih.gov/Disorders/AllDisorders/Thoracic-Outlet-Syndrome-InformationPage. Accessed on $14^{\text {th }}$ November 2019.

3. Grunebach H, Arnold MW, Lum YW. Thoracic outlet syndrome. Vasc Med. 2015;20(5):493-5.

4. Chavhan GB, Vaishnavi B, Muthusami P, Towbin AJ, Borschel GH. MRI of thoracic outlet syndrome in children. Pediatr Radiol. 2017;47(10):1222-34.

5. Thetter O, Van Dongen RJ, Barwegen MG. The thoracic outlet compression syndrome and its vascular complications. Zentralblattfür Chirurgie. 1985;110(8):449-56.

6. Sell, James J, Rael, Jesse R, Orrison, William W. Rotational vertebrobasilar insufficiency as a component of thoracic outlet syndrome resulting in transient blindness. J Neurosurg. 1994;81(4):617-9.

7. Nishibe T, Kunihara T, Kudo FA, Adachi A, Shiiya $\mathrm{N}$, Murashita $\mathrm{T}$, et al. Arterial thoracic outlet syndrome with embolic cerebral infarction. Report of a case. Panminerva Med. 2000;42(4):295-7.

8. Franklin GM. Work-related neurogenic thoracic outlet syndrome diagnosis and treatment. Phys Med Rehabil Clin No Am. 2015;26(3):551-61.

9. EI FN, Nunez-Arguelles J, Castillo J. Neck and brain transitory vascular compression causing neurological complications. Results of surgical treatment on 1,300 patients. The J Cardio Surg. 1996;37(6 Suppl 1):15566.

Cite this article as: Chavan N, Mahapatra S, Ruhil M, Mohokar S. Incidental finding of thoracic outlet syndrome in a case of right tubal ruptured ectopic pregnancy. Int J Reprod Contracept Obstet Gynecol 2020;9:3880-2. 